\title{
SOCIOLINGUÍSTICA CULTURAL
}

Marcelo Moraes Caetano

mmcaetano@hotmail.com

\section{Introduzindo o assunto: características gerais da comunicação segundo a sociolinguística interacional}

A sociolinguística interacional procura demonstrar que a fala em interação está sujeita a mudanças e interpretações que podem variar de acordo com o comportamento linguístico e paralinguístico (como pistas e marcadores), que, por sua vez, é controlado por (e controlador de) inúmeros contextos específicos, e estes podem ser mais bem apreendidos pelos participantes (ou mesmo pelo analista) em função da situação informada ou do "sentido comunicado" específicos que se estejam perquirindo.

Assim, através de apreensões empíricas, revelam-se dados que permitam analisar melhor os modelos de interação, levando em conta o falante e o ouvinte in loco, como evidenciaram Sacks, Jefferson e Schlegloff (1974), em função de comportamentos específicos na interação que se estiver observando de per se, como demonstrou Scheflen (1964).

Desse modo, com pistas linguísticas e paralinguísticas, partese de convenções sociais que interferem sobremaneira no tipo de atividade de fala - a unidade básica da comunicação (cf. GOFFMAN, 1974). Além disso, a presença das implicaturas (cf. GRICE ${ }^{26}$, apud LEVINSON, 2007, p. 125-201), que podem ser convencionais (não ligadas a itens léxicos específicos, mas a condições de uso sociais específicas) ou lexicais (ligadas a palavras e itens sintáticos), faz o ouvinte inferir certas interpretações num contexto (MARCONDES, 2005, p. 29-35).

\footnotetext{
${ }^{26}$ Apesar disso, a abordagem griciana de comunicação requer certa idealização prévia que, de certa forma, vai de encontro a algumas correntes sociointeracionistas, embora, em outros momentos, seja inestimável sua contribuição ao construto teórico da mesma linguística sociointeracional.
} 
Com efeito, a noção de comunicação como comportamento, proposta por Gumperz (1982, capítulos 1 a 5), e que estará sendo feita aqui, não partirá de fatos e evidências apriorísticos, mas, pelo contrário, buscará, na apreensão empírica dos dados apresentados, o que normalmente se denomina de "fenômenos sociolinguísticos" (GUMPERZ, 1982), respostas pertinentes à dinâmica do processo de comunicação, que, como foi dito, altera-se à medida que os participantes interagem, processo este que não é estanque ou determinado exclusivamente por fatores variacionistas (cf. WEINREICH, LABOV \& HERZOG, s/d) prévios ou por noções idealistas que, portanto, pressuporiam um modelo de certa forma "estático" de comunicação, na medida em que tal modelo poderia ser previamente delimitado, antes mesmo de os dados empíricos serem recolhidos numa situação comunicada específica.

Portanto, a noção de comunicação, neste trabalho, não é a de código, ou, como se conhece nas famosas metáforas, a de "telégrafo" ou "conduto", que, embora levasse em conta as inferências, era a base da noção de comunicação proposta por Searle (1969) e por Grice (1980) que, como dito, pressupõem como pano de fundo "a crença na harmonia como fundamental à comunicação, tanto na dimensão do código, quanto na dos mecanismos inferenciais" (MARTINS, p. 2002, p. 99).

A noção de comunicação aqui abordada será a da linguística sociointeracional, que não coloca tanta ênfase na intenção ou mesmo nas condições (étnicas, sociais, culturais, de nível de instrução) do falante, mas, em vez disso, demonstra que a comunicação é um comportamento, um ato de troca, uma práxis, não sendo tão fundamental considerar-se, para se comunicar algo, se houve ou não intenção prévia. Tanto a informação emitida com intenção quanto aquela em que houver ausência desse fator serão, na sociointeracional, concebidas como comunicação.

Essa diferença epistemológica é importante, porque pressupõe que se conheçam conceitos específicos que ajudarão na análise dos dados conversacionais colhidos, tais como esquemas, enquadres, footing $^{27}$, sequencialidade, pares adjacentes, preferência, convenções

${ }^{27} \mathrm{O}$ termo footing é bastante vasto e requer uma série de explicações para ser compreendido. Goffman (1981, p. 128, apud TELLES, 2002, p. 185) o descreve como "outra forma de fala de 
e pistas de contextualização, tomada de turno, reparo, sobreposição e outros. Todos esses conceitos serão usados para a construção da análise que compõe a parte 2 deste trabalho

O modelo interacional, portanto, considera a noção de informação situada, como foi dito, e, pois, depende menos do código que do contexto, já que os significados e as interpretações são implícitos e frequentemente indiretos, o que constrói uma variedade comunicativa que necessita de um aparato específico para a compreensão dos fenômenos linguísticos então ocorridos. Não se trata apenas, pois, da análise da capacidade ou competência comunicativa de participantes se compreenderem mutuamente levando em conta fatores convencionais diretos ou indiretos, como, de certa forma, propunha Searle (1975). Muito mais do que isso, o que vai ocorrer é o fato de que:

Podemos, portanto, referir-nos à comunicação humana como canalizada e restringida por um sistema multinivelar de sinais verbais e não verbais, que são adquiridos, ao longo da vida, automaticamente produzidos e intimamente coordenados. Os insights mais importantes sobre a respeito de como tais sinais afetam a comunicação verbal se originaram em estudos sobre a coordenação entre falantes e ouvintes (KENDON; HARRIS; KEY, 1975)

Assim, a sociointeracional não possui visão idealizada do processo comunicativo, mas o vê como uma construção que os participantes, durante a interação, promovem (SCHIFFRIN, 1990):

Os participantes de uma conversa, por exemplo, têm expectativas convencionais sobre o que é considerado normal e o que é considerado marcado em termos de ritmo, volume da voz, entoação e estilo de discurso. Ao sinalizar uma atividade de fala, o falante também sinaliza as pressuposições sociais em termos das quais uma mensagem deve ser interpretada. (GUMPERZ, 1982)

Portanto, para Gumperz, Goffman e mesmo Bateson (1972), a conversa não é um evento coeso, mas uma sucessão de atividades em contexto e em enquadres e esquemas específicos. O conhecimento e

uma mudança em nosso enquadre dos eventos", ou ainda "uma mudança no alinhamento que assumimos para nós mesmos e para os outros presentes, expressa na forma em que conduzimos a produção ou a recepção de uma elocução". Em outras palavras, ele o descreve como a "habilidade de um falante competente ir e vir, mantendo em ação diferentes círculos" (GOFFMAN, 1985, p. 157, apud TELLES, 2002, p. 185). Utilizaremos o conceito na nossa análise da entrevista central deste trabalho. 
a aplicação das noções propostas por esses teóricos e por outros é o principal objetivo a ser levado a termo neste artigo, centradas numa conversa específica, que será mais detalhada adiante.

\section{Objetivo}

O objetivo deste trabalho é mostrar como os participantes de uma conversa institucionalizada (entrevista a um órgão da imprensa) constroem, espontaneamente, laços de afetividade e solidariedade, com base nos conceitos de comunicação formulados teórica e empiricamente pela linguística interacional. Ademais, pretende-se demonstrar como essas construções interativas vão se fazendo, face a face, de maneira gradativa, segundo a tomada de turnos e com base ainda nos demais conceitos, como os de enquadres, tópicos, alinhamentos e outros pertinentes às questões cunhadas, levantadas e aprofundadas pelos sociolinguistas interpretativos.

A entrevista foi dada por Ana Maria Machado, membro da Academia Brasileira de Letras, a Marcelo Moraes Caetano, em maio de 2009. Nela, vão ser abordados os principais conceitos utilizados em Sociolinguística interacional acima expostos, como foi dito, de modo que se demonstre, ao fim do artigo, e com base na descrição teórica dos fenômenos sociolinguísticos presentes na entrevista, a eficácia e a pertinência desse construto na análise de uma conversa espontânea em que os participantes compartilhavam esquemas e enquadres em comum, criando-se a interação comunicativa que era desejada. Será demonstrado, ainda, que, quando, num contexto, as expectativas são compartilhadas, mesmo sobreposições, reparos ou respostas despreferidas podem construir uma interação harmônica e amigável.

\subsection{Posicionamento teórico: principais termos utilizados na análise}

O termo enquadre (ou enquadre interativo) diz respeito a elementos contextuais que são incluídos e excluídos nas interações verbais ou não verbais. Por meio dele, elocuções, movimentos, gestos, pausas podem ser interpretados como pertencentes a um aconte- 
cimento, como "brincadeira", "introspecção", "briga" e assim por diante. Ele diz respeito, pois, ao que está acontecendo numa interação. (TANNEN \& WALLAT, apud TELLES, p. 188; TANNEN, 1985; TELLES, 2002, p. 260) "O que está acontecendo aqui e agora?" (TELLES, 2002, p. 107) Também, pode receber nomenclaturas como "script", "esquema", "protótipo", "atividade de fala", modelo e módulo.

Esquema (ou esquema de conhecimento em interação) é usado para se fazer referência

às expectativas dos participantes acerca de pessoas, objetos, eventos e cenários do mundo, fazendo distinção, portanto, entre os sentido desse termo e os alinhamentos que são negociados em uma interação específica. (TANNEN \& WALLAT, 187, p. 189, apud TELLES, 2002, p. 261).

Alinhamento é um termo que pode referir-se tanto à posição física propriamente dita dos participantes uns com os outros (aproximando-se da noção de alterações proxêmicas), como ao alinhamento contextual entre os interlocutores, como eles se apresentam socialmente uns aos outros, suas condições, qualificações, como corroboram ou resistem às apresentações dos participantes (ratificados ou não ratificados) ou circunstantes. Na segunda acepção, o termo se aproxima da noção de footing (GOFFMAN, 1974). Pode ser entendido como "o alinhamento ou porte ou posicionamento ou postura ou projeção pessoal do participante" (GOFMMAN, apud TELLES, 2002, p. 262). Segundo os autores, ainda, uma mudança de footing pode ser interpretada como outra forma de mudarem-se os enquadres interativos.

Sequência ou sequencialidade é basicamente a ideia de "como uma coisa leva à outra" (HAVE, 1999, p. 113)

Os participantes, ao produzirem elocuções e gestos paralinguísticos, não agem aleatoriamente, mas levam em conta o que o outro ou os outros disseram previamente (LODER, SALIMEN, MÜLLER, apud LODER \& JUNG, 2008, p. 40)

A noção de adjacência ou de pares adjacentes (SACKS, 1992), muito ligada à noção de sequência, demonstra que há um ordenamento entre as duas elocuções que são proferidas, pois foi observado que algumas elocuções se organizam sequencialmente em 
pares, sendo a segunda relevada condicionalmente (SCHEGLOFF, 1968) pela primeira . Assim, é natural que a uma pergunta se siga uma resposta, (a pergunta é a primeira parte do par e a resposta é a segunda).

À noção acima, ainda se liga outra fundamental: a de preferência. Como lembra Sacks (1992, apud LODER, SALIMEN, MÜLLER, 2008, p. 51), "dada uma elocução qualquer, classificada de qualquer modo, ela admite mais do que uma coisa que pode ser feita a seguir, mas estabelece que não é qualquer coisa que pode ser feita a seguir". Levinson ainda destaca que respostas ou atividades preferidas são não marcadas, enquanto as despreferidas são marcadas (LEVINSON, 2007). Assim, por exemplo, se se liga para uma pessoa e se fala "alô", não se espera que ela fale "eu tenho que sair imediatamente", sem sequer responder com a ação preferida o primeiro fenômeno sociolinguístico, que seria responder "alô", para, depois, se necessário, completar com a elocução que enquadra uma impossibilidade de falar naquele momento. Autores como Atkinson e Heritage (1984, p. 53) alertam que as respostas despreferidas tendem a ser suavizadas e seguidas de pausas, hesitações e indiretividades.

\section{Metodologia}

Para a detecção de dados de uma interação face a face, foi colhida uma hora e meia de entrevista à acadêmica Ana Maria Machado, como foi dito. A entrevista, resultado dessa gravação, vai publicada na íntegra, anexa, em apêndice, neste trabalho.

Para a análise sociointeracionista da entrevista, foram escolhidos os 7 últimos minutos desta, pelo fato de que se considerou que, a partir do fim da interação, os participantes estavam mais espontâneos, e suas respostas eram, portanto, mais sujeitas à apreensão de pistas e inferências igualmente espontâneas, que permitiam conclusões mais apropriadas e válidas sobre o que está sob a égide da Sociolinguística interacional. Tal parte da entrevista não foi publicada, mas o DVD resultado da gravação vai, também, anexo em apêndice neste artigo, a fim de que seja comparado com a transcrição linguística que comporá a unidade 2 do presente artigo. 
Com os conceitos provenientes da Sociolinguística interacional, portanto, e, eventualmente, com outros oriundos de áreas em que possa haver intercessão em alguns pontos (como a Pragmática), será feita breve análise do trecho conversacional face a face em tela. Os dados empíricos levantados, repita-se, conjugados e articulados ao arcabouço teórico fornecido pelos teóricos da linguagem em interação, pretendem formular algumas conclusões que demonstrem que a criação de expectativas e enquadres é de importância capital para a consecução bem-sucedida de uma conversa ${ }^{28}$, já que os participantes compartilham esquemas que lhes permitem entendimento mútuo.

\section{Análise de entrevista concedida por Ana Maria Machado a Marcelo Moraes Caetano}

\section{TRECHO}

\begin{tabular}{|c|c|c|}
\hline $\begin{array}{l}01 \\
02\end{array}$ & MARCELO & $\begin{array}{l}\text { em alguma situação você perde:: tem alguma coisa que } \\
\text { te faça perder a calma ou a elegância] }\end{array}$ \\
\hline 03 & ANA MARIA & com frequência] \\
\hline 04 & MARCELO & o que que te faz perder \\
\hline $\begin{array}{l}05 \\
06 \\
07 \\
08\end{array}$ & ANA MARIA & $\begin{array}{l}\text { (2.0) me sentir acuada:: basicamente eu viro bicho } \\
\text { quando eu me sinto acuada quando eu não tenho mais } \\
\text { espaço:: pra sair de outra maneira então eu tenho que } \\
\text { pular no pescoço. }\end{array}$ \\
\hline 09 & MARCELO & você é faz parte do seu temperamento $\downarrow$ \\
\hline $\begin{array}{l}10 \\
11\end{array}$ & ANA MARIA & $\begin{array}{l}\text { faz parte do meu temperamento } \downarrow>\text { eu sei sei que aquilo } \\
\text { passa com rapidez }<\end{array}$ \\
\hline $\begin{array}{l}12 \\
13\end{array}$ & MARCELO & $\begin{array}{l}=\text { você }>\text { você é mística } \uparrow \text { você tem algum misticismo } \downarrow< \\
\text { alguma [religião } \uparrow\end{array}$ \\
\hline $\begin{array}{l}14 \\
15 \\
\end{array}$ & ANA MARIA & $\begin{array}{l}\text { [não não sou mística } \downarrow \text { mas eu::: > respeito uma transcen- } \\
\text { dência né } \downarrow<\end{array}$ \\
\hline $\begin{array}{l}17 \\
18 \\
19\end{array}$ & MARCELO & $\begin{array}{l}\text { = vc é capricórnio né de } 24 \text { de: de dezembro você escre- } \\
\text { veu um livro "Canteiros de Saturno": tem alguma [co- } \\
\text { nexão } \uparrow\end{array}$ \\
\hline 20 & ANA MARIA & [não isso puramente por acaso \\
\hline 21 & MARCELO & $=$ foi por acaso \\
\hline $\begin{array}{l}22 \\
23\end{array}$ & ANA MARIA & $\begin{array}{l}\text { =puramente por acaso porque alguém tinha me falado } \\
\text { negócio de Saturno,de eu ser Capricórnio }\end{array}$ \\
\hline 24 & MARCELO & [porque Saturno é o \\
\hline $\begin{array}{l}25 \\
26\end{array}$ & ANA MARIA & $\begin{array}{l}\text { aí eu me interessei nisso olhei nunca tinha visto AÍ re- } \\
\text { solvi fazer um livro que tivesse um livro sempre uma }\end{array}$ \\
\hline
\end{tabular}

${ }^{28} \mathrm{~A}$ entrevista será a base empírica para o levantamento desses dados. 


\section{Faculdade de FormaÇão de PROFESSORES}

\begin{tabular}{|c|c|c|}
\hline $\begin{array}{l}27 \\
28 \\
29 \\
30 \\
31\end{array}$ & & $\begin{array}{l}\text { história tem um ponto de partida assim tem um desafio } \\
\text { né:: e eu resolvi inventar um livro que TODOS os per- } \\
\text { sonagens tivessem uma carta astral prévia } \downarrow:: \text { então isso } \\
\text { não entrou no livro mas eu sei cada um deles quando } \\
\text { nas[ceu }\end{array}$ \\
\hline 32 & MARCELO & [huhum \\
\hline $\begin{array}{l}33 \\
34 \\
35\end{array}$ & ANA MARIA & $\begin{array}{l}\text { >o que que [era e o que que devia FAZER e como devia } \\
\text { se comportar de acordo com a carta astral que tinha< }\end{array}$ \\
\hline 36 & MARCELO & [huhum \\
\hline $\begin{array}{l}37 \\
38 \\
\end{array}$ & ANA MARIA & $\begin{array}{l}\text { aí comprei um kit de fazer carta astral ((risos)) só sei } \\
\text { que fiz [e pronto }\end{array}$ \\
\hline 39 & MARCELO & [e fez isso e isso no "Canteiro de Saturno" \\
\hline 40 & ANA MARIA & $=$ "Canteiro de Saturno" foi uma brincadeira \\
\hline $\begin{array}{l}41 \\
42 \\
43 \\
44\end{array}$ & MARCELO & $\begin{array}{l}\text { (1.2) Bom como é que vc acha que as crianças e os jo- } \\
\text { vens hoje estão se relacionando com os livros } \downarrow \text { como é } \\
\text { que ta a relação HOJE do jovem e da criança >é aquilo } \\
\text { que vc falou< se o jovem] }\end{array}$ \\
\hline 45 & ANA MARIA & [não dá pra:: pra generalizar né $\downarrow$ \\
\hline 46 & MARCELO & =é não mas o que você o que que você acha $\downarrow$ \\
\hline $\begin{array}{l}47 \\
48\end{array}$ & ANA MARIA & $\begin{array}{l}\text { <pega a lista dos mais vendidos>: três deles são >"Cre- } \\
\text { púsculo" não sei o que e papapa né } \downarrow<\end{array}$ \\
\hline 49 & MARCELO & hum \\
\hline $\begin{array}{l}50 \\
51\end{array}$ & ANA MARIA & $\begin{array}{l}\text { são apresentados como livros juvenis } \downarrow \text { antes disso foi } \\
\text { "A Bússola Dourada" }\end{array}$ \\
\hline 52 & MARCELO & huhum \\
\hline $\begin{array}{l}53 \\
54\end{array}$ & ANA MARIA & $\begin{array}{l}\text { antes disso "Harry Potter" antes disso ["Senhor dos A- } \\
\text { néis"] }\end{array}$ \\
\hline 55 & MARCELO & ["Senhor dos Anéis"] \\
\hline 56 & ANA MARIA & e todo mundo diz [que jovem não lê mais \\
\hline 57 & MARCELO & ["Crônicas de Nárnia" \\
\hline 58 & ANA MARIA & É que jovem não tá lendo hoje em dia jovem não lê \\
\hline 59 & ANA MARIA & então acho que os adultos estão lendo [( ) \\
\hline $\begin{array}{l}60 \\
61 \\
\end{array}$ & MARCELO & $\begin{array}{l}\text { [eu acho que os temas é que é que eles se interessam [é } \\
\text { que:: }\end{array}$ \\
\hline 62 & ANA MARIA & ,[é \\
\hline $\begin{array}{l}63 \\
64 \\
65\end{array}$ & MARCELO & $\begin{array}{l}\text { <não são o que eles acham> que deveria ser que eles não } \\
\text { tão começando a ler Machado de Assis eu acho que é is- } \\
\text { so que acontece }\end{array}$ \\
\hline 66 & ANA MARIA & $=$ mas Machado de Assis $\uparrow$ não é leitura de jovem \\
\hline 67 & MARCELO & $=$ =é mas não era pra ser mesmo \\
\hline 68 & ANA MARIA & $=$ não era pra ser \\
\hline $\begin{array}{l}69 \\
70\end{array}$ & MARCELO & $\begin{array}{l}=\text { isso dizer ah o jovem não lê porque o jovem não lê } \\
\text { Machado de Assis [mas ele não tem }\end{array}$ \\
\hline 71 & ANA MARIA & [não lê o que o professor [quer \\
\hline 72 & MARCELO & [ele não tem ele não tem [maturidade... pra ler \\
\hline 73 & ANA MARIA & [não lê o que o pai ta querendo \\
\hline
\end{tabular}




\section{DEPARTAMENTO DE LETRAS}

\begin{tabular}{|c|c|c|}
\hline 74 & ANA MARIA & [não lê o que o adulto quer \\
\hline $\begin{array}{l}75 \\
76 \\
77\end{array}$ & MARCELO & $\begin{array}{l}\text { [é ele não tem realmente maturidade pra ler Machado de } \\
\text { Assis entender as sutilezas [de "O Alienista" }\end{array}$ \\
\hline 78 & ANA MARIA & [não \\
\hline $\begin{array}{l}79 \\
80\end{array}$ & MARCELO & $\begin{array}{l}\text { como é que ele vai entender Quincas Borba,ele não tem } \\
\text { como mesmo né }\end{array}$ \\
\hline $\begin{array}{l}81 \\
82 \\
83 \\
84\end{array}$ & ANA MARIA & $\begin{array}{l}\text { mas entende dependendo da idade entende perfeitamen- } \\
\text { te um conto como "Pai contra mãe" por exemplo: de- } \\
\text { pende do que que você dá de Machado de Assis [pra ler }\end{array}$ \\
\hline $\begin{array}{l}85 \\
86 \\
87\end{array}$ & MARCELO & $\begin{array}{l}\text { [è verdade,verdade } \downarrow \text {... que circunstâncias são capazes } \\
\text { de de dar um golpe dar um baque por exemplo na sua } \\
\text { esperança } \downarrow\end{array}$ \\
\hline 88 & ANA MARIA & (1.0) hh problema de saúde \\
\hline 89 & MARCELO & (1.0) isso te da um-::: \\
\hline 90 & ANA MARIA & hh $<\ldots$ dá to cansada mesmo $\downarrow>$ hh \\
\hline 91 & MARCELO & (1.5) bom vou te [pedir- \\
\hline $\begin{array}{l}92 \\
93 \\
94 \\
95\end{array}$ & ANA MARIA & $\begin{array}{l}\text { [seja comigo seja com quem eu amo né::: não sei se da o } \\
\text { o baque na esperança mas hh um baque é um baque não } \\
\text { tira completamente ( ) mas um desânimo } \downarrow\end{array}$ \\
\hline $\begin{array}{l}96 \\
97 \\
98\end{array}$ & MARCELO & $\begin{array}{l}\text { huhum .. diz uma frase:: ou um pensamento:: alguma } \\
\text { coisa que você tenha aí como apanágio ou como- ((gesto } \\
\text { de mãos para cima)) }\end{array}$ \\
\hline 99 & ANA MARIA & olha tem várias \\
\hline 100 & MARCELO & pode ser sua,ou] \\
\hline $\begin{array}{l}101 \\
102 \\
103\end{array}$ & ANA MARIA & $\begin{array}{l}\text { [eu,em geral escolho uma das duas do Drummond:: uma } \\
\text { do Galbraith >qual que cê quer } \uparrow<((\text { risos })) \text { ou as duas } \uparrow\end{array}$ \\
\hline 104 & MARCELO & quero as duas ((risos)) \\
\hline $\begin{array}{l}105 \\
106 \\
107\end{array}$ & ANA MARIA & $\begin{array}{l}\text { o Galbraith diz: que ele gostaria de }<\text { com o trabalho de- } \\
\text { le:: levar um pouco de:> conforto pros aflitos e >um } \\
\text { pouco de aflição pros confortados< }\end{array}$ \\
\hline 108 & MARCELO & $=$ nossa \\
\hline $\begin{array}{l}109 \\
110 \\
111 \\
\end{array}$ & ANA MARIA & $\begin{array}{l}\text { e o Drummond diz que "este é o segredo e a arte do bem } \\
\text { viver... uma fuga relativa... uma não muito estouvada } \\
\text { confraternização" } \downarrow\end{array}$ \\
\hline $\begin{array}{l}112 \\
113 \\
114 \\
115 \\
116 \\
117\end{array}$ & MARCELO & $\begin{array}{l}\text { ótimas frases muito boas } \downarrow \text { ipra terminar eu preciso que } \\
\text { você me de é uma um pedido nosso lá da livraria que } \\
\text { você me dê um uma definição conceito uma palavra um } \\
\text { enfim alguma um sinônimo pra CULTURA o que é cul- } \\
\text { tura pra você }\end{array}$ \\
\hline $\begin{array}{l}118 \\
119\end{array}$ & ANA MARIA & $\begin{array}{l}\text { (2.5) hh tem que ser uma palavra assim ou pode ser [u- } \\
\text { ma reflexão }\end{array}$ \\
\hline $\begin{array}{l}120 \\
121\end{array}$ & MARCELO & $\begin{array}{l}\text { Lpode ser o que você quiser pode ser uma reflexão sobre } \\
\text { cultura }\end{array}$ \\
\hline
\end{tabular}




\begin{tabular}{|c|c|c|}
\hline $\begin{array}{l}122 \\
123 \\
124 \\
125 \\
126 \\
127 \\
128 \\
129 \\
130 \\
131 \\
132\end{array}$ & ANA MARIA & $\begin{array}{l}\text { tem uma reflexão que eu gosto muito: que originalmente } \\
\text { nem é minha ela parte de uma observação etimológica } \\
\text { que o Alfredo Bosi faz:: ah ele lembra que colonização: } \\
\text { ocupação de um espaço: para o plantio para o colono en- } \\
\text { fim para a AGRICULTURA ((risos)) é uma aposta no } \\
\text { futuro:: e que o futuro é a cultura } \downarrow \text { :: esse URA ((gesto } \\
\text { com uma mão como se estivesse pegando algo peque- } \\
\text { no)) era o particípio futuro no latim morituri te salutant } \\
\text { eram os ah os gladiadores quer dizer aqueles que vão } \\
\text { morrer te [saúdam }\end{array}$ \\
\hline 133 & MARCELO & [nascituro \\
\hline $\begin{array}{l}134 \\
135 \\
136 \\
137 \\
138 \\
139\end{array}$ & ANA MARIA & $\begin{array}{l}\text { [nascituro aquele que vai nascer então cultura é aquilo } \\
\text { que vai ser colhido:: hh e não é aquilo que vai ser colhi- } \\
\text { do SÓ na agricultura porque aÍ é só no campo Cultura é } \\
\text { aquilo que plantado num determinado momento pela } \\
\text { humanidade vai construir o futuro }\end{array}$ \\
\hline 140 & MARCELO & então a cultura tem esse olho no- \\
\hline 141 & ANA MARIA & $=$ tem o olho pro futuro \\
\hline 142 & MARCELO & pro futuro ótimo interessantíssimo muito bom \\
\hline 143 & ANA MARIA & huhum \\
\hline 144 & MARCELO & bom Ana muitíssimo obrigado \\
\hline 145 & ANA MARIA & obrigada a você \\
\hline 146 & MARCELO & , pela entrevista pela sua paciência \\
\hline $\begin{array}{l}147 \\
148 \\
149 \\
150\end{array}$ & ANA MARIA & $\begin{array}{l}\text { eu queria registrar não precisa ser assim mas é muito ra- } \\
\text { ro a gente ter uma entrevista em que o entrevistador veio } \\
\text { tão preparado com perguntas tão inteligentes }\end{array}$ \\
\hline 151 & MARCELO & obrigado obrigado \\
\hline 152 & ANA MARIA & trouxe a revista $\uparrow$ ah livro teu \\
\hline 153 & MARCELO & são livros meus \\
\hline 154 & & esse é prefácio do Secchin \\
\hline 155 & ANA MARIA & que $\uparrow \underline{\text { ótimo }}$ \\
\hline 156 & MARCELO & do Marcos Almir Madeira e do Niskier \\
\hline 157 & ANA MARIA & que bom que ótimo \\
\hline 158 & MARCELO & vim trazer pra você \\
\hline
\end{tabular}

Por se tratar de uma situação social ritualizada, já que se trata de entrevista a ser publicada em meios de imprensa nacional, filmadas e gravadas por equipes técnicas, o macroenquadre do evento é exatamente o de uma "entrevista". Assim, durante quase todo o tempo, os interlocutores se alinharam respectivamente como entrevistador (Marcelo) e entrevistada (Ana Maria). Apenas na linha 152, a tomada de turno é feita pela entrevistada, que faz uma pergunta ao entrevistador "(“ah, livro teu?”), o que reforça que o evento anteri- 
ormente enquadrado como entrevista, com os papéis claramente delimitados (como se mostrou) havia acabado, na verdade desde a linha 142. Também ocorre uma inversão dos alinhamentos (a entrevistada faz a pergunta ao entrevistador) na linha 102. Mas, logo em seguida, os alinhamentos originais são reassumidos e ratificados.

Voltando à linha 142, a partir dela, com efeito, os participantes adquirem footings diferentes, e passam a interagir mais livremente numa conversa informal, em que cada um pode, sem necessidade de seguir scripts prévios, comportar-se linguística e paralinguisticamente com mais fluidez e espontaneidade.

Apesar do macroenquadre "entrevista", há outros enquadres que são sinalizados ao longo do evento social. Por exemplo, em muitos momentos a entrevistada sinaliza estar num enquadre de "introspecção", "reflexão", sinalizando que o entrevistador respeite as suas hesitações como provenientes desse esquema de conhecimento, que deveria ser compartilhado por ambos. Isso ocorre, por exemplo, nos turnos (nas linhas) 05 a 08 (quando a entrevistada fala de como se sente em situações limite), 88, 90, 92 a 95 (quando ela fala sobre questões de saúde). No turno da linha 142, embora a entrevistada fala explicitamente a palavra "reflexão", na verdade o enquadre é de "citação", pois ela cita uma autoridade literária (Alfredo Bosi) para responder ao que foi pedido no turno anterior pelo entrevistador (linha 113 a 116): uma definição ou um conceito para "cultura".

Quanto às sequencialidades, por ser uma entrevista, como se demonstrou, todos os pares são adjacentes, e a maioria das respostas foi preferida em relação à relevância condicional. Na pergunta da linha 12, no entanto, a resposta foi despreferida, pois foi uma negação. Note-se que essa negação, como sinalizaram Atkinson e Heritage (qv acima) foi realmente atenuada com um tom de voz mais baixo e descendente e a velocidade da resposta foi mais lenta. Por sua vez, a pergunta das linhas 18 e 19, que terão também respostas despreferidas, foram feitas sem nenhum atenuante: muito pelo contrário, a resposta da entrevistada (linha 20 e ratificada na linha 22) foi imediata, alta, incisiva e, como se disse, reforçada na linha 22, após a pergunta ser feita novamente na linha 21. Apesar dessa aparente incisividade, a seguir, a entrevistada, numa narrativa, suaviza a resposta com um turno bastante longo (das linhas 25 a 31), reforçando-a nas linhas 33 
a 35, 37 e 38 e, finalmente, suavizando totalmente na linha 39, quando enquadra a incisividade de que o livro fora "puramente por acaso" (linha 20) com o que diz agora que: "Canteiros de Saturno foi uma brincadeira" (linha 40, o grifo é meu). Outros enquadres de "brincadeira" podem ser encontrados, como nas linhas 101 a 103 (Ana Maria), ratificadas pelo turno de Marcelo (1. 103)

Nas linhas 92 a 95, Ana Maria faz um reparo ao que Marcelo chama de "golpe" ou "baque" na "esperança" (linhas 85 a 87), quando,por uma tautologia, daquelas que Levinson e Grice tão bem estudaram como não infratoras da máxima da quantidade nem da qualidade, pois, num contexto, eram perfeitamente informativas, ela diz (linhas 92 a 95) "não sei se dá o baque na esperança, mas, hh, um baque é um baque não tira completamente, mas um desânimo" (os grifos são originais, demonstrando ênfase da entrevistada nas palavra sublinhadas).

Das linhas 53 a 62, há várias sobreposições. Os dois participantes quase falam simultaneamente por todo esse tempo. No entanto, tais sobreposições, no contexto em questão, não simbolizam discordância ou impolidez, mas, pelo contrário, insinuam uma forte cumplicidade entre os interlocutores, concordando e listando uma série de livros que demonstram como ambos acham que os livros infanto-juvenis são os mais vendidos, o que comprova que o jovem, ao contrário do que apregoa o senso comum, continua a se interessar pela leitura.

Todas essas sobreposições, que podem ser enquadradas como "listagem", respondem ratificando a pergunta feita nas linhas 41 e 42 ("Bom, como é que você acha que as crianças e os jovens estão se relacionando hoje com os livros?"). Assim sendo, como ficou dito, as sobreposições não chegam a ser interrupções, mas ratificações recíprocas da concordância dos participantes sobre a resposta dada àquela pergunta.

O mesmo fenômeno sociolinguístico ocorrerá nas linhas 132 (Ana Maria) 133 (Marcelo) e 134 (Ana Maria), em que o enquadre "exemplo" é reforçado com palavras que comprovam que os sufixos -ura e -uro (que compõem a palavra "cultura", cf. linha 137) são particípios futuros do latim, presentes em outros vocábulos como (“agricultura", 1.127; "nascituro" ls. 133 e 134; "morituri” 1. 130). 
Também se pode enquadrar o turno que vai das linhas 105 a 107 e 109 a 111, além daquele que vai da 122 à 141, como um enquadre de "aula", dentro do macroenquadre da "entrevista".

A partir da linha 143, Marcelo, com um marcador linguístico (uma interjeição que significa concordância) demonstra o fim da entrevista. A partir dessa linha, ocorre conversa informal, e,como ficou registrado, Ana Maria chega a tomar o primeiro par da sequência algumas vezes, o que só ocorreu uma vez durante o enquadre da "entrevista". Por essa razão, pode-se dizer que, a partir de 143, há uma "pós-entrevista".

Dessa forma, com a cooperação dos interlocutores, criou-se um forte vínculo de solidariedade conversacional que permitiu que mesmo respostas despreferidas ou sobreposições prolongadas e interrupções não fossem interpretadas como inadequadas. Em vez disso, as atividades de fala e os alinhamentos foram negociados de tal forma que passaram a convergir para uma pista de contextualização de que os interlocutores estavam compartilhando, sim, não apenas um esquema de expectativas, como também uma vontade mútua de colaborar com a construção da conversa em si, culminando com um evento linguístico prazeroso e cortês.

\section{Conclusão}

No presente trabalho procurou-se analisar uma conversa (entrevista) em que os fenômenos sociolinguísticos advieram do fato de os participantes compartilharem esquemas e enquadres em comum, criando-se a interação comunicativa amigável e solidária, mesmo em um evento social ritualizado e institucional.

\section{REFERÊNCIAS BIBLIOGRÁFICAS}

ATKINSON. J. Maxwell \& HERITAGE, John. Structures of social action. Cambridge. Cambride University Press, 1984.

BATESON. G. Steps to an ecology so mind. New York: Ballantine, 1972.

GOFFMAN. E. Frame Analysis. New York: Harper and Row, 1974. 
Forms of talk. Philadelphia: University of Pennsylvania Press. In: TELLES, Branca R.; GARCEZ, P. (Orgs.). Sociolinguística interacional. São Paulo: Loyola, 2002.

GRICE, H.P. Lógica e conversação. In: DASCAL, M. (Org.). Fundamentos metodológicos da linguística: Pragmática. São Paulo: Do Autor, 1980.

GUMPERZ, Discourse strategies. Cambridge. Cambridge University Press. In: In: TELLES, Branca. R \& GARCEZ, P. (Orgs.). Sociolinguística interacional. São Paulo: Loyola 2002.

HAVE, Paulten. Doing conversation analysis. A practical guide. Londres: Sage, 1985.

KENDON, A. HARRIS, R.M. \& KEY, M. R. (Orgs.) Organization of behavior in face-to-face interaction. Haia: Mouton. In: GUMPERZ, Discourse strategies. Cambridge: Cambridge University Press, 1975.

LEVINSON S. C. Pragmática. 1. ed. São Paulo: Martins Fontes, 2007.

LODER, L.; SALIMEN, P. G.; MÜLLER, M. Noções fundamentais: sequencialidade, adjacência e preferência. In: LODER, L. L.; JUNG, M. N. Fala em interação social: introdução à análise da conversa etnometodológica. 1. ed. Campinas: Mercado das Letras, 2008.

MARTINS, C. A indeterminação do significado nos estudos sociopragmáticos: divergências teórico-metodológicas. In: D.E.L.T.A., 181: 1, 2002, p. 87-116.

SACKS, Harvey. Lectures on conversation. Oxford: Basil Blackwell, 1992.

; SCHEGLOFF, E.; JEFFERSON, G. A simplest systematics for the organization osf turn-taking for conversation. Language, 50, p. 696-735, 2002.

SCHEGLOFF, Emanuel. Sequencing inconversation openings. American Antropologist, v. 70, p. 1075-1095, 1968.

TELLES, Branca R.; GARCEZ, P. (Orgs.). Sociolinguística interacional. São Paulo: Loyola, 2002. 
SCHEFLEN. A. The significance of posture in communication systems. Psychiatry 27. In: TELLES, Branca. R \& GARCEZ, P. (Orgs.). Sociolinguística interacional. São Paulo: Loyola, 2002.

SCHIFFRIN, D. The management of a co-operative self during argument: the role of opinions and stories. In: A. D. GRIMSHAW (ed.) Conflict talk: sociolinguistic investigations of arguments in conversation. Cambridge: Cambridge University Press, 1990.

SEARLE. J. R. Speech Acts. Cambridge: Cambridge University Press, 1969.

. Indirect Speech Acts. In. COLE, P.; MORGAN, J. L. (Orgs.). Syntax and Semantics, vol. 3, 59-82. New York Academic Press, 1975.

TANNEN, Deborah. Frames and eschemas ininteraction. In: RASKIN, V. (org.). Quaderni di semântica round tabelediscussion on framne/script semantics, Quaderni di semanttica, 6, p. 326-35, 1985.

; WALLAT, Cynthia. In: TELLES, Branca. R \& GARCEZ, P. (Orgs.). Sociolinguística interacional. São Paulo. Loyola, 2002.

TELLES, Branca. R \& GARCEZ, P. (Orgs.). Sociolinguística interacional. São Paulo: Loyola, 2002.

WEINREICH, V; LABOV, W; HERZOG, M. Empirical foundations for a Theory of language. In: LEHMAN, W.P \& MALKIEL Y. (eds.). Directions for historical linguistics. Austin \& London: University of Texas Press, p. 95-288, s/d. 